and the highest frequencies of sinuses $(\mathrm{p}=0.031)$, laryngeal $(\mathrm{p}=0.026)$ and CNS $(p=0.020)$ involvement.

Long-term outcomes were available only in 113 patients. A low long-term mortality rate $(8,7.1 \%$ deaths) was noted (mean follow-up of $66.6 \pm 30.6$ months), significantly higher in anti-MPO positive patients $7(21.9 \%)$ when compared to anti-PR3 positive $1(1.6 \%)$ and ANCA negative $0(0 \%)(p<0.001)$. Nevertheless, the highest number of relapses/years were associated with anti-PR3 positivity $(0.7 \pm 1.3$ vs $0.1 \pm 0.3$ in anti-MPO and $0.4 \pm 0.7$ in ANCA negative, $p=0.012)$. At multivariate analysis, anti-PR3 pattern resulted an independent predictive factor of relapses ( $p=0.0036$, OR 5.8 , IC95\%: $1.1-29$ ).

Conclusions: Our study confirms the hypothesis that each ANCA pattern could define a specific disease subset with different clinical manifestations and outcomes in AAV. Furthermore, in our cohort we observed a lower rate of recurrence and a better long term survival $(92.9 \%)$ than in literature.

References:

[1] Mahr A et al; French Vasculitis Study Group (FVSG) and the European Vasculitis Society (EUVAS): Revisiting the classification of clinical phenotypes of anti-neutrophil cytoplasmic antibody-associated vasculitis: a cluster analysis. Ann Rheum Dis. 2013 Jun;72(6):1003-10.

Disclosure of Interest: None declared

DOI: 10.1136/annrheumdis-2017-eular.5606

\section{FRI0338 THERAPEUTIC CONFORMITY TO GUIDELINES AND DRUG-APPROVAL IN ADAMANTIADES-BEHCET'S DISEASE: A RETROSPECTIVE ANALYSIS OF A MIDDLE-EUROPEAN COHORT}

T.M. Moosmann ${ }^{1}$, C. Veraar ${ }^{1}$, A. Frech ${ }^{2}$, G. Ratzinger ${ }^{3}$, B. Teuchner ${ }^{4}$, G. Fraedrich ${ }^{2}, \mathrm{M}$. Schirmer ${ }^{1} .{ }^{1}$ Internal Medicine VI; ${ }^{2}$ Vascular Surgery; ${ }^{3}$ Dermatology; ${ }^{4}$ Ophthalmology, Lkh - Medizinische Universität Innsbruck, Innsbruck, Austria

Background: Adamantiades-Behcet's disease (ABD) is a chronic systemic vasculitic disease. Because of multiorgan involvement with diagnostic and therapeutic challenges for physicians, treatment decisions can be very difficult. Objectives: To retrospectively assess the use of medication for ABD-therapy in view of 1.) current guidelines and 2.) approval by authorities in a Middle-European tertiary care center.

Methods: Data between 1997 and 2016 from a Middle-European ABD-cohort were retrospectively analysed. First, medical treatment was evaluated for conformity with the EULAR-recommendations for ABD-management and the anti-TNF therapy recommendations by Sfikakis et al. $(1,2)$. Second, medical treatment was evaluated for use according to indications approved by authorities. Therefore official prescribing informations of the Bundesamt für Sicherheit im Gesundheitswesen (BASG)/European Medicines Agency (EMA), exemplary for Europe, and the Food and Drug Administration (FDA), exemplary for the USA, were screened (3-5). The study was approved by the local ethics committee.

Results: A total of 174 medical interventions were identified in 76 patients. Until 2008, treatment of ABD was based only on few clinical trials. According to EULAR-recommendations $93,7 \%$ were considered as being treated appropriately, including $55.2 \%$ of therapeutic approaches exactly matching the recommendations. $88.9 \%$ of TNF-inhibitors were indicated according to the anti-TNF-therapy recommendations $(n=8 / 9)$. Out of 27 used drugs only prednisolone was approved by BASG/EMA- and FDA-authorities for a general indication including ABD, and cyclosporin A had the specific BASG/EMA-indication for ABD-uveitis. Another 12 medications had the indications for different symptoms of $A B D$, and thirteen medications were not authority-approved for any ABD-treatment.

Conclusions: Approvals by BASG/EMA- and FDA-authorities are often missing the indication of $A B D$. Therefore physicians not only face the complexity of $A B D$ as a rare multiorgan disease, but also have to treat their ABD-patients with unapproved drugs. We propose that medications recommended by international guidelines for the management of rare diseases should be recognized by BASG/EMA- and FDA-authorities, even in case of low evidence.

\section{References:}

[1] Hatemi G, Silman A, Bang D, et al. EULAR recommendations for the management of Behçet disease. AnnRheumDis. 2008;67:1656.

[2] Sfikakis PP, Markomichelakis N, Alpsoy E et al. Anti-TNF therapy in the management of Behçet's disease-review and basis for recommendations. Rheumatol. 2007;46:736.

[3] BASG. Arzneispezialitätenregister, 20/09/2016 [Internet]. https:// aspregister.basg.gv.at/aspregister/faces/aspregister.jspx?_afrLoop= 31622307107626619\& afrWindowMode $=0$ \& adf.ctrl-state=kimc6lskg 4

[4] EMA. European Medicines Agency - Find medicine - European public assessment reports [Internet] http://www.ema.europa.eu/ema/index.jsp?curl=pages/ medicines/landing/epar_search.jsp\&mid=WC0b01ac058001d124.

[5] FDA. Drugs@FDA: FDA Approved Drug Products, citated 20.09.2016 [Internet]. Available from: http://www.accessdata.fda.gov/scripts/cder/drugsatfda/ index.cfm?fuseaction=Search.Search Drug Name.

Disclosure of Interest: None declared

DOI: 10.1136/annrheumdis-2017-eular.5070

\section{FRI0339 B CELL REPOPULATION KINETICS AFTER RITUXIMAB TREATMENT IN ANCA-ASSOCIATED VASCULITIDES COMPARED TO RHEUMATOID ARTHRITIS, AND CONNECTIVE TISSUE DISEASES: A LONGITUDINAL OBSERVATIONAL STUDY ON 120 PATIENTS}

J. Thiel, M. Rizzi, A. Troilo, U. Salzer, A. Venhoff, R. Lorenzetti, R. Voll, N. Venhoff. Department of Rheumatology and Clinical Immunology, University Medical Center Freiburg, Freiburg, Germany

Background: $B$ cell depletion with rituximab (RTX) is approved for treatment of rheumatoid arthritis (RA) and ANCA-associated vasculitides (AAV). Recently, RTX has been shown to be effective in AAV maintenance therapy, but an optimal RTX treatment schedule is unknown and the time to $B$ cell repopulation after RTX has not been studied.

Objectives: To compare kinetics of B cell repopulation after RTX treatment in AAV, RA and connective tissue diseases (CTD) to improve the design of RTX-retreatment schedules in AAV and other autoimmune diseases.

Methods: Retrospective single-center analysis of patients with AAV, RA or CTD treated with RTX and a follow-up of $>9$ months were included. B-cell-repopulation was defined as a peripheral B-cell count $>0.5 \%$ and $>5 / \mu$ l. Prolonged B cell depletion was defined by a B cell repopulation starting later than 12 months after RTX treatment.

Results: 120 patients were included in the study. Sixty-six patients had AAV with 55 classified as granulomatosis with polyangiitis (GPA) or microscopic polyangiitis (MPA) and 11 as eosinophilic granulomatosis with polyangiitis (EGPA). Thirty-five patients had RA and 19 were treated with RTX because of CTD. There were no significant differences between the groups regarding age and sex. Most patients were treated with RTX $1000 \mathrm{mg}$ twice, two weeks apart. Cumulative CYC doses were higher in patients with AAV or CTD than in RA patients. In RA and CTD we observed a B-cell repopulation in all patients $(100 \%)$ while only 33 AAV patients $(50 \%)$ had started B-cell repopulation $(p<0.0001) .93 \%$ of the RA and $88 \%$ of the CTD patients showed a normal repopulation within the first 12 months after RTX compared to only $10 \%$ in GPA and $0 \%$ in EGPA $(p<0.0001)$. Mean time to repopulation was significantly longer in GPA/MPA (21 months) and in EGPA (20 months) compared to RA ( 8.5 months) and CTD (8.7 months). Median time of persistent depletion was 26 months in GPA/MPA, 21 months in EGPA compared to 9 months in RA and 8 months in CTD $(p<0.0001)$. In 25 AAV patients $B$ cell depletion persisted longer than 24 months (mean time $4.4 \pm 18.1$ years). In ten of 55 GPA/MPA patients B-cells were still depleted 4 years, in six patients even after more than 5 years after only one RTX treatment cycle. One patient had a complete B cell depletion even 8 years after the second RTX treatment. Immunoglobulin production was affected by RTX-treatment with a significant decrease in IgG, IgA and IgM compared to baseline values in GPA/MPA, but not in RA or CTD. In EGPA only IgM declined significantly. Significantly more patients with GPA/MPA and EGPA developed a hypogammaglobulinemia ( $\mathrm{gGG}<7 \mathrm{~g} / \mathrm{L}$, $\operatorname{lgM}<0.4 \mathrm{~g} / \mathrm{L})$. In some $\mathrm{AAV}$ patients hypogammaglobulinemia became clinically relevant and required IVIG treatment. Conclusions: In contrast to RA and CTD, in AAV RTX induces long-lasting depletion of $B$ cells that is associated with decreased antibody production. This observation points towards potential defects in the $B$ cell compartment in $A A V$ and has important implications for the design of maintenance treatment schedules using RTX.

Disclosure of Interest: J. Thiel Consultant for: Roche, M. Rizzi: None declared, A. Troilo: None declared, U. Salzer: None declared, A. Venhoff: None declared, R. Lorenzetti: None declared, R. Voll Consultant for: Roche, N. Venhoff Consultant for: Roche

DOI: 10.1136/annrheumdis-2017-eular.4783

\section{FRI0340 B-CELL ACTIVATING FACTOR AS A BIOMARKER OF ACTIVITY OF SYSTEMIC NECROTIZING VASCULITIS (SNV)}

L. Petelytska ${ }^{1}, \underline{\text { O. laremenko }}{ }^{1}, \mathrm{~K}$. laremenko ${ }^{2} \cdot{ }^{1}$ Bogomolets National Medical University; ${ }^{2}$ Oleksandrivska City Clinical Hospital, Kyiv, Ukraine

Background: Non-specific marker of inflammation such as C-reactive protein (CRP) and the erythrocyte sedimentation rate (ESR) have limited value in assessment of vasculitis activity. Normal ESR values do not exclude the diagnosis of active vasculitis, and its increase may be due to concomitant infection.

Objectives: To evaluate the levels of B-cell activating factor and ESR in pts with different activity of SNV.

Methods: The serum levels of B-cell activating factor (BAFF) and ESR were measured in 48 pts with SNV (granulomatosis with polyangiitis - 22, eosinophilic granulomatosis with polyangiitis -9 , microscopic polyangiitis -6 , polyarteritis nodosa - 11). The 48 pts included 18 male and 30 female with median age 49; 24 were positive for cytoplasmic antineutrophil cytoplasmic antibodies and 11 for perinuclear antineutrophil cytoplasmic antibodies. At screening, 9 pts were without any treatment, 26 pts were receiving glucocorticoids (GCs) and 13 pts were receiving some cytotoxic agents and GCs. Clinical activities of pts were calculated by the Birmingham Vasculitis Activity Score (BVAS). All pts were divided into 3 groups according to the value of BVAS: group 1 (BVAS $\leq 11 ; n=12$ ), group 2 (BVAS $=12-23 ; n=23$ ) and group 3 (BVAS $\geq 24 ; n=13$ ). The outcomes of this study were the differences in marker levels between groups estimated by analysis of the absolute changes in marker levels and the areas under receiver operating characteristic $(\mathrm{ROC})$ curves. 
Results: The levels of BAFF were significantly higher in group $3(0.88 \pm 0.19$ $\mathrm{ng} / \mathrm{ml})$ compared with group $1(0.68 \pm 0.13 \mathrm{ng} / \mathrm{ml}, \mathrm{p}<0.05)$, but did not distinguish from the group $2(0.90 \pm 0.35)$. There were not significant differences in ESR between groups. ROC analysis indicated that the AUC for ESR is $0.63 \pm 0.10$ $(p=0.17)$ and for BAFF $-0.72 \pm 0.12(p<0.05)$, which indicates fair capacity for BAFF differentiate groups of pts with low activity or remission of SNV and pts with severe SNV (sensitivity - $61.5 \%$, specificity - $88.9 \%$ ), while it was poor for ESR (sensitivity - $85.7 \%$, specificity - 46.4\%).

Conclusions: There are significant differences in levels of BAFF between pts with $B V A S \geq 24$ and pts with $B V A S \leq 11$. According to ROC analysis evaluation of serum BAFF level distinguishes pts with active SNV from pts with low activity or remission better than determination of ESR.

Disclosure of Interest: None declared

DOI: 10.1136/annrheumdis-2017-eular.2200

\section{FRI0341 CLINICO-PATHOLOGICAL DISCREPANCIES AND CAUSES OF DEATH IN TAKAYASU ARTERITIS: A RETROSPECTIVE ANALYSIS OF 60 FATAL CASES}

O. Zimba ${ }^{1}$, M. Bagriy ${ }^{2}{ }^{1}$ the Department of Internal Medicine, Danylo Halytsky Lviv National Medical University, Lviv; ${ }^{2}$ Department of Pathological Anatomy, Ivano-Frankivsk National Medical University, Ivano-Frankivsk, Ukraine

Background: Takayasu arteritis (TA) may present with a wide spectrum of symptoms common to other diseases leading to delayed or missed diagnosis. Objectives: To investigate the rate of undiagnosed clinically cases of TA, and provide a detailed analysis of the wrong diagnoses and the underlying causes of death.

Methods: A retrospective clinicopathological analysis of sixty autopsy cases (52 males and 8 females aged 18 to 45 years) of TA over period of 11 years have been performed. The median age at disease onset was 25, 7 years.

Results: In 33 cases (55\%), TA was not diagnosed during the clinical stages but only in autopsy. The most common incorrect clinical diagnosis was atherosclerosis of the aorta and its branches (celiac trunk, renal, mesenteric and iliac arteries) that has misdiagnosed in 14 cases $(42.4 \%)$ of TA. TA was misdiagnosed as myocardial infarction/ischaemic heart disease in $5(15.1 \%)$, perforated peptic ulcer in $3(9.1 \%)$, polyarteritis nodosa in $3(9.1 \%)$, and infective endocarditis in 2 cases $(6.1 \%)$. There were other discrepancies in 6 cases $(18.2 \%)$; in these cases, cerebral haemorrhage, rheumatic heart disease, pulmonary embolism, pheochromocytoma, chronic glomerulonephritis and lung cancer were the wrong clinical diagnoses. The leading position in the mortality structure due to TA belongs to septic shock that observed in 19 cases $(31.7 \%)$ due to peritonitis/acute abdomen caused by mesenteric artery occlusion with subsequent intestinal necrosis in $12(63.1 \%)$, lower limb gangrene in $6(31.6 \%)$, and prosthetic aortic graft infection in $1(5.3 \%)$. The second-leading cause of death was acute heart failure due to myocardial infarction, and renovascular arterial hypertension (25\%). The third common cause of death was haemorrhagic shock in 14 cases $(23.3 \%)$. The acute bleeding was caused by ruptured aortic aneurysm in abdominal part in 6 cases $(42.8 \%)$ and ascending aorta with cardiac tamponade in $4(28.6 \%)$. In 2 cases $(14.3 \%)$, the source of hemorrhage was ulcers of gastrointestinal tract. The surgery has complicated by lethal bleeding in 2 cases (14.3\%). In other patients, causes of death were cerebral haemorrhage in $6(10 \%)$, renal failure in $3(5 \%)$, respiratory failure in $1(1.7 \%)$, and revascularization syndrome in $1(1.7 \%)$. In one case, TA coexisted with scleroma of larynx, and asphyxia was direct cause of death.

Conclusions: Our date show a high number of cases of TA (55\%) that were identified at autopsy but were not diagnosed clinically. It can be assumed that aortic atherosclerosis, myocardial infarction/ischaemic heart disease were the most common wrong diagnoses in TA. The leading causes of death in TA are septic shock, acute heart failure, and haemorrhagic shock. In addition, it should be noted that in our series of autopsy cases of TA, males $(86,7 \%)$ were most frequently affected compared with results other investigations. Interestingly, that the correct diagnosis of TA was established before death in all females' cases. It seems to be a trend to miss the clinical diagnosis of TA in male patients.

Disclosure of Interest: None declared

DOI: 10.1136/annrheumdis-2017-eular.6182

\section{FRI0342 DISTRIBUTION OF VASCULITIDES IN EASTERN MEDITERRANEAN: RESULTS OF A PROSPECTIVE COHORT}

O. Karadag, A. Erden, E.D. Batu, E. Bilgin, A.O. Uyaroglu, E. Seyhoglu, E.C. Bolek, E. Firat, H.E. Sonmez, S.Z. Arici, L. Kilic, A. Akdogan, S.A. Bilgen, S. Kiraz, I. Ertenli, S. Ozen. Hacettepe University Vasculitis Center, Ankara, Turkey

Background: The ethnic and geographical differences have been commented on, mainly from European data. We lack large data sets from the eastern part of Europe.

Objectives: This study is aimed to present the distribution of vasculitides in the Pediatric and Adult Vasculitis patient groups.

Methods: Hacettepe University is one of the main referral centers in the capital of Turkey, serving approximately 470,000 adult and pediatric patients/a year. Hacettepe University Vasculitis Centre (HUVAC) was established to organize a prospective cohort in 2014. All patients starting from October 2014 have been recorded to the database. Additionally electronic patient recording database between October 2014-December 2016 was searched for the patients having any of the 10th revision of the International Statistical Classification of Diseases (ICD)-10 code for the particular vasculitis. The study group of Hacettepe University Vasculitis Centre (HUVAC) re-evaluated the ascertained patients' hospital records to review their diagnosis according to the 2012 revised Chapel Hill nomenclature criteria.

Results: A total of 1196 patients had been newly followed in this period. 271 (22.7\%) of them were pediatric patients and $31.8 \%$ of them were newly diagnosed. The leading vasculitis among adult patients was Behcet's Disease whereas in pediatric patients it was HSP/lgA Vasculitis (Table). Granulomatous polyangiitis was the most common small vessel vasculitis in adults. Takayasu arteritis was more frequent than giant cell arteritis among the adult patients. There was a female predominance in patients with large vessel vasculitis.

During prospective follow up, $22(1.9 \%)$ patients deceased; 7 due to the primary disease, 6 due to infections, 7 due to cardio and cerebrovascular diseases.

Table, Distribution and gender of Adult and Paediatric Vasculitides Patients

\begin{tabular}{|c|c|c|}
\hline \multicolumn{3}{|l|}{ Adult Patients $(\mathrm{n}=925)$} \\
\hline Type & Frequency, $\%$ & Female, $\%$ \\
\hline Behcet's Disease & 50.5 & 53.7 \\
\hline ANCA Associated Vasculitis & 11.9 & 46.4 \\
\hline - $\quad$ GPA & 8.9 & 47.9 \\
\hline EGPA & 2.2 & 52.3 \\
\hline - MPA & 0.8 & 57.1 \\
\hline Takayasu's Arteritis & 10.7 & 90 \\
\hline IgA Vasculitis & 4.3 & 47.5 \\
\hline Giant Cell Arteritis & 3.8 & 71.4 \\
\hline Cutaneous Vasculitis & 3.2 & 70 \\
\hline Polvarteritis Nodosa & 3.1 & 44.8 \\
\hline IgG4 Related Disease & 2.8 & 48.2 \\
\hline CTD-Secondary Vasculitis & 2.3 & 71.4 \\
\hline Polimyalgia Rheumatica & 2.2 & 95 \\
\hline Primary CNS Vasculitis & 0.8 & 42.8 \\
\hline Isolated Aortitis & 0.8 & 50 \\
\hline Cryoglobulinemic Vasculitis & 0.4 & 25 \\
\hline Others & 3.2 & 57.3 \\
\hline \multicolumn{3}{|l|}{ Paediatric patients $(n=271)$} \\
\hline Type & Frequency,\% & Female, $\%$ \\
\hline IgA Vasculitis & 46.5 & \begin{tabular}{|l|}
45.6 \\
\end{tabular} \\
\hline Behcet's Disease & 22.5 & 45.9 \\
\hline Kawasaki Disease & 17.3 & 45.6 \\
\hline Polyarteritis Nodosa & 3.7 & 50.0 \\
\hline Takayasu's.Arteritis & 2.6 & 100 \\
\hline ANCA Associated Vasculitis & 1.5 & 75 \\
\hline Vasculopathies (SAVI, DADA2) & 1.5 & 37.5 \\
\hline Others & 4.4 & 52.3 \\
\hline
\end{tabular}

Conclusions: Behcet's Disease is the most frequent vasculitis in Turkey and more than half of the patients had organ/system involvements. GPA is the most common small vessel vasculitis whereas Microscopic polyangiitis is very rare. Among children Kawasaki was less and Behçet's disease markedly more when compared to Western European figures. Even though this study is a single-center one, the number of annual admitted patients of our hospital along with more than 2 years-prospective recruitment, reflects the true burden of vasculitides in Turkey, at the cross-roads between Europe and Middle East.

Disclosure of Interest: None declared

DOI: 10.1136/annrheumdis-2017-eular.5322

\section{FRI0343 COGNITIVE DISORDERS IN BEHCCET'S DISEASE: SOME CLINICAL AND PATHOGENESIS RELATIONS}

P. Ovcharov $^{1}$, T. Lisitsyna ${ }^{1}$, D. Veltishchev ${ }^{2}$, D. Burenchev ${ }^{3}$, D. Ishchenko ${ }^{2}$ ${ }^{\text {O. Seravina }}{ }^{2}$, O. Kovalevskaya ${ }^{2}$, Z. Alekberova ${ }^{1}$, E. Nasonov ${ }^{1} .{ }^{1}$ Nasonova Research Institute of Rheumatology, Moscow, Russia; ${ }^{2}$ Moscow Research Institute of Psychiatry; ${ }^{3}$ City policlinic No. 12 Moscow Department of Health, Moscow, Russian Federation

Background: the cognitive disorders (CD) is a special psychopathological problem for Behçet's Disease (BD) patients. The causes of CD aren't enough investigated. Anxiety/depressive disorders and primary neural parenchymal lesions due to BD usually related to $C D$ in these patients.

Objectives: to determine the prevalence of $\mathrm{CD}$ in $\mathrm{BD}$ patients and its associations with some clinical and magnetic resonance imaging (MRI) scan features.

Methods: the investigation has been realized in accordance with the interdisciplinary program "Stress factors and mental disorders in immune-mediated inflammatory rheumatic diseases".

$106 \mathrm{BD}$ patients were enrolled in the study. The majority of patients were men $(72,6 \%)$, natives of the North Caucasus $(51,9 \%)$, with mean age $(M \pm m) 33,3 \pm 0,98$ years. All the patients met the criteria of the International Study Group for BD (1990) classification. The disease activity was assessed by scoring system BDCAF.

$\mathrm{CD}$ were diagnosed with psychology and neuropsychology methods. Mental disorders (MD) were diagnosed by psychiatrist in accordance with the ICD-10 in semi-structured interview. The severity of depression and anxiety was evaluated 